THE $11^{\text {TH }}$ EDITION OF

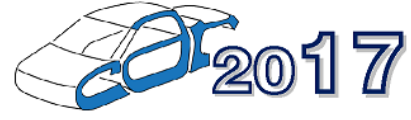

The International Congress of Automotive and Transport Engineering

MOBILITY ENGINEERING AND ENVIRONMENT

November 8-10, 2017

\title{
Research using advanced engineering methods concerning automotive waste disposal in road traffic and transport specialized unit from Cluj-Napoca
}

\author{
Adela-Ioana BORZAN, Doru-Laurean BĂLDEAN* \\ ${ }^{1}$ Technical University of Cluj-Napoca, Romania \\ *Corresponding author: doru.baldean@auto.utcluj.ro \\ Article history \\ Received 12.07.2017 \\ Accepted 25.09.2017 \\ DOI https://doi.org/10.26825/bup.ar.2017.004
}

\begin{abstract}
Waste management problem in daily life and especially in automotive sector is one of the main concerns in relation with pollution issue. The most important aspect consists in how are disposed different materials from car services and transportation units which are realizing specific maintenance and repairing operations. In the majority of these situations there are materials and components that have to be disposed of, but current habit is to throw them away with the rest of the common garbage. The organic materials are not difficult to process because the nature itself deals with them very easily by decomposition, but other complex and heavily processed components from automotive industry are hard to deal with. Main objective of the paper is to outline an advanced method in engineering aided waste disposal of automotive waste products from transport unit in Cluj-Napoca. Specific objectives consists in idea presentation of proposed method in automotive waste field and an experimental validation developed in the private cooperation with vehicle operating and transport provider from Cluj-Napoca.
\end{abstract}

\section{Introduction}

Widespread application of plastic is accompanied by negative effect of wastes production constituting a serious environmental problem. An important role in this area is played by the introduction, in recent years, in the countries of the European Union stronger restrictions on the disposal of organic waste and the requirement to achieve high levels of recovery and recycling of certain waste groups, in which waste plastics constitute a large part. Waste packages, as well as building and automotive wastes are the main sources of plastics wastes. Waste plastics at first should be recycled by mechanical or chemical recycling and when it is not cost effective utilized 
for energy recovery. According to Plastics Europe Foundation $25.1 \mathrm{mln} \mathrm{Mg}$ of plastic waste were produced in 2011, $6.3 \mathrm{mln} \mathrm{Mg}$ of these wastes were recycled and $8.6 \mathrm{mln} \mathrm{Mg}$ was utilized for energy recovery. The remaining part of the waste plastics was disposed at landfills. Only about $8 \%$ of plastic waste is recovered as a result of selective collection from the stream of municipal wastes. Approximately $23 \%$ of these wastes are recycled and there is a systematic increase in the field for several years. Another $15 \%$ is utilized for energy recovery through the production of solid recovered fuels. In some countries, such as Switzerland, Denmark, Sweden, Belgium, Austria and Netherlands participation of energy recovery exceed level of $60 \%$. Energy recovery from waste plastics is mostly realized in waste incineration plants and cement kilns. There are also performed attempts to co-combustion of waste plastics in power plants using fluidized bed boilers and pulverized fuel boilers. In some countries, such as Japan and Germany, the waste plastics are used in metallurgical processes [1].

Because of the unique properties of plastic materials, they are used in a wide range of application sectors, such as packaging, building and construction, automotive and aeronautics, electrical and electronic equipment, agriculture, leisure and sports equipment or medical and health products, to help us to live and build a more sustainable world. Distribution of European plastics demand by segment in 2015 is shown in figure 1 and figure 2 [2].

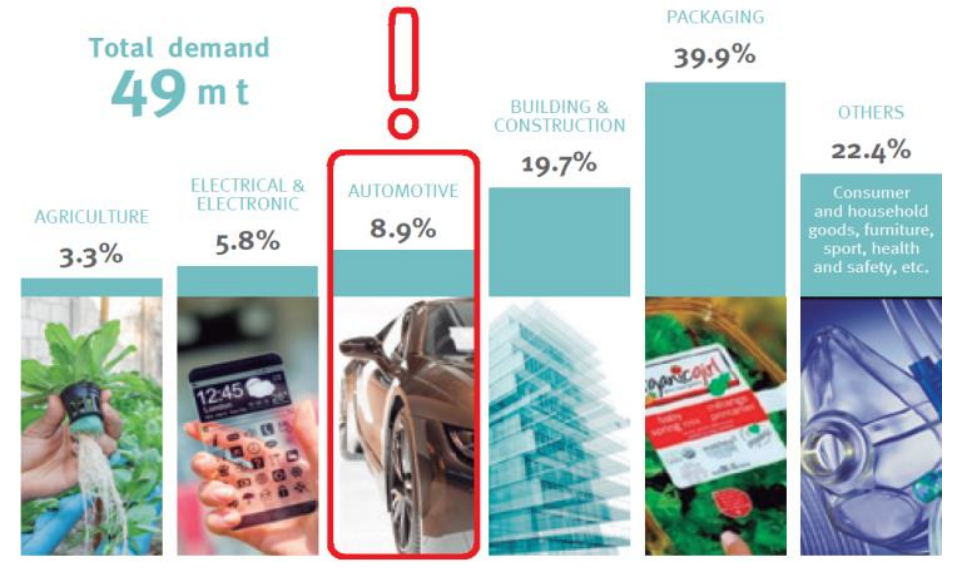

Figure 1. Plastic materials demand main market sectors [2].

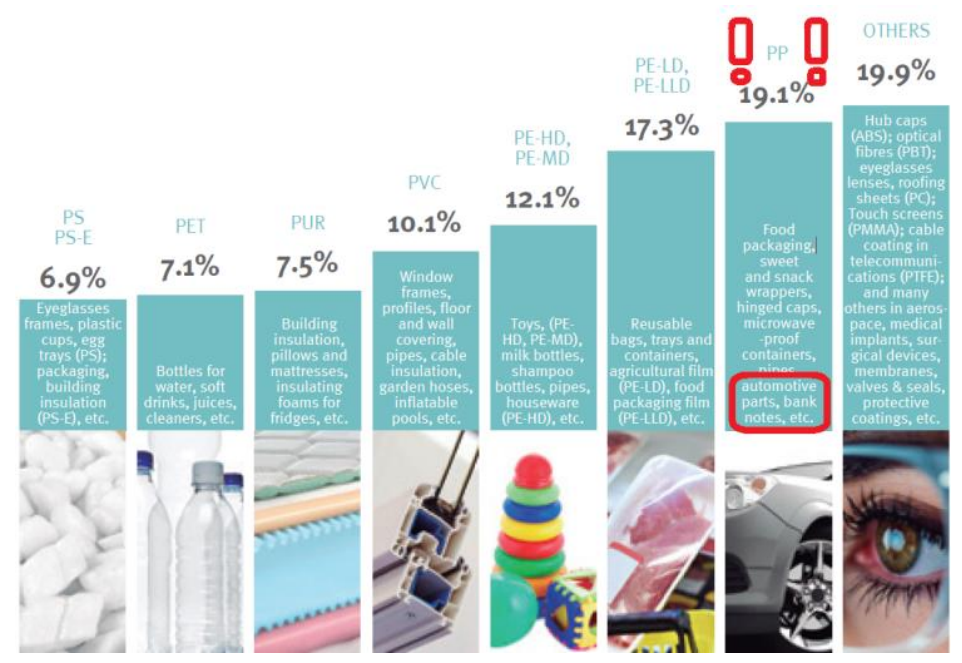

Figure 2. Plastic materials main fields of applications [2].

European plastics demand (EU-28+NO/CH) by polymer type 2015 is shown in figure 3 and they are used afterwards to manufacture a wide variety of new products as is represented in figure 4 [2]. 


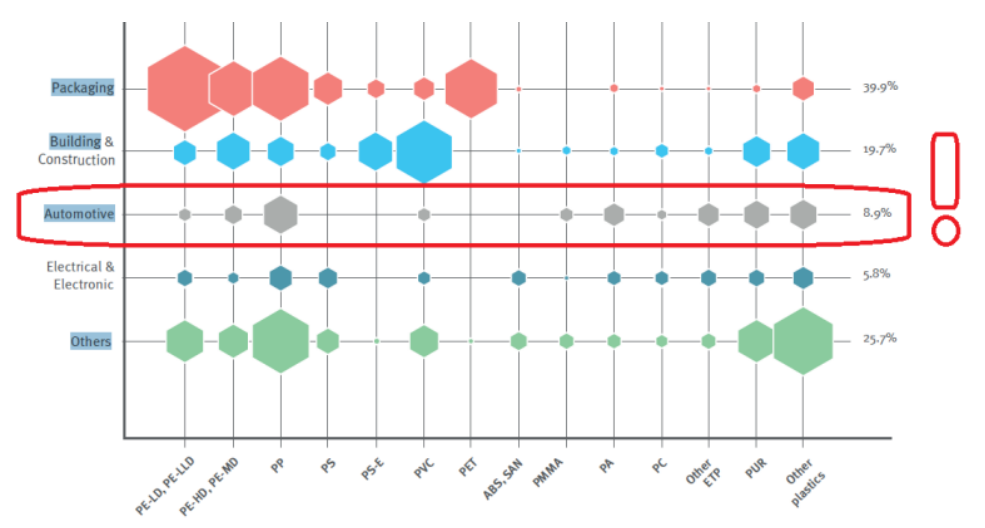

Figure 3. Plastics demand by polymer and market segment [2].

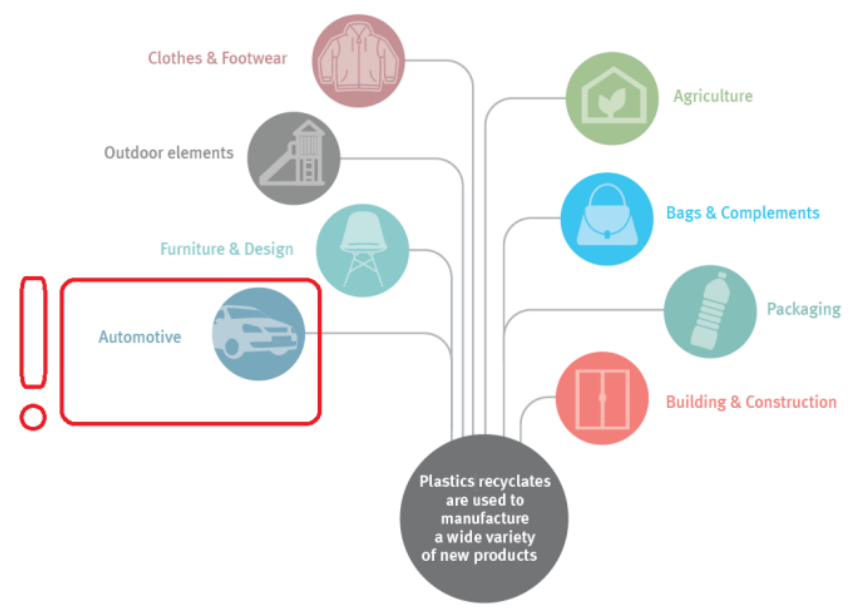

Figure 4. Fields of applications for recycling plastics disposals [2].

The present paper shows the possibility of energy recovery of automotive waste products and organizational and engineering aspects of this procedure.

\section{Methodology and materials}

\subsection{Methodology}

By using the latest technologies available it is outlined an innovative method for automotive waste disposal management system operation, consisting in elements and procedures which interact between them. Analyzing automotive waste impact on ecosystems we can understand and discuss the problem of disposing all the pollutant materials and components. The present paper develops an engineering method with computer aided waste management and automotive products disposal in order to facilitate a better and cleaner perspective for modern society. The idea is analyzed theoretically and finally tested in experimental conditions. The influence of computer processing power on waste disposal and management systems has a positive side. The usage of computer aided waste processing and automotive waste products recycle is pointed out during the present work development.

\subsection{Materials}

The used equipment in automotive waste products recovery and conversion for developing the practical part of present work were thermal devices for combustion process management, radiators and data recording equipment. Also there was a whole thermodynamic system for advanced 
measuring as well as electronic post-processing applications for an engineered management of wastes.

Figure 5 shows the relations between the main components of thermal conversion system for automotive waste products in order to develop the research activity staged up by the present paper [3].

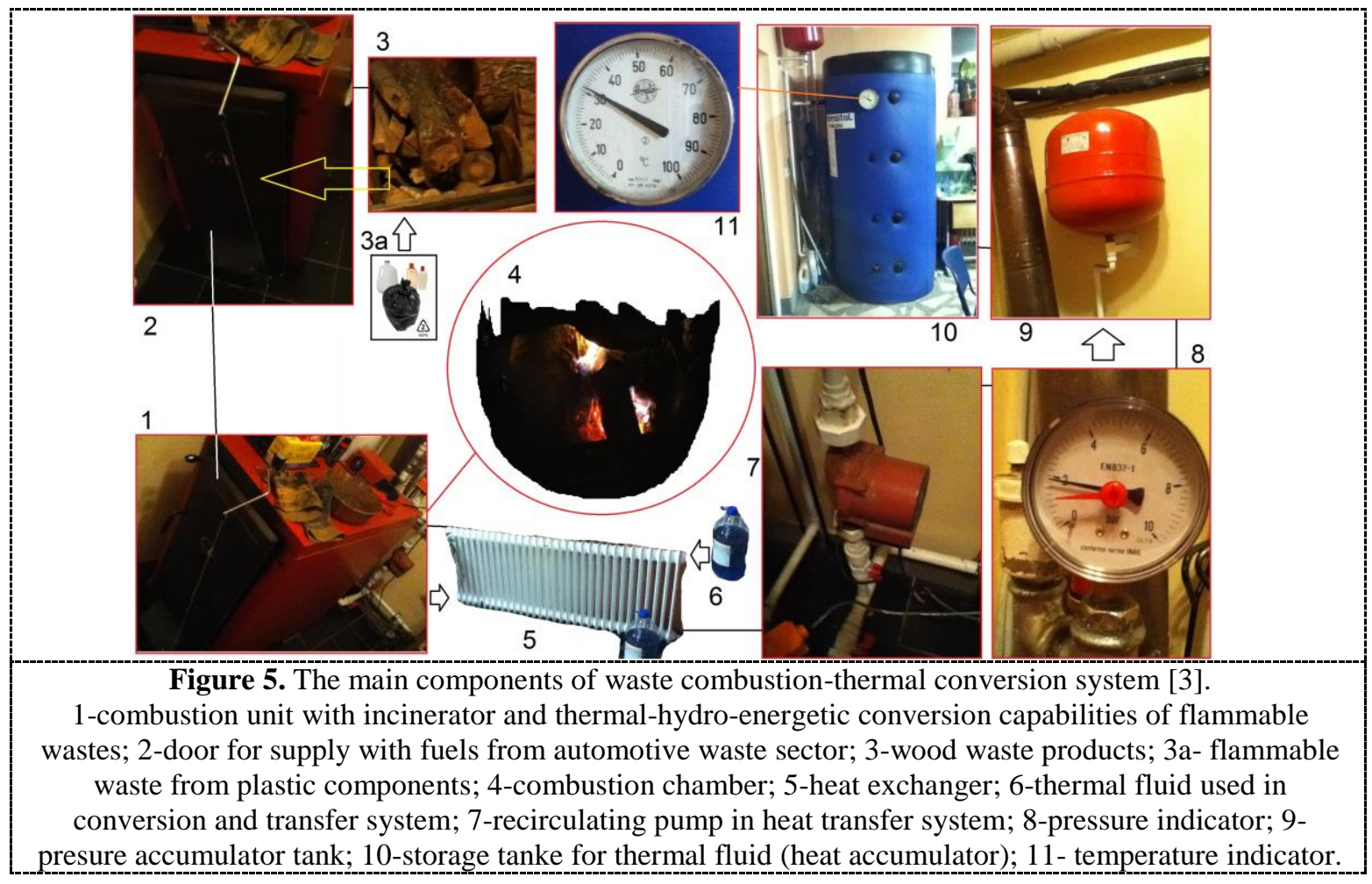

\subsection{Mathematics and calculus}

The First Law of Thermodynamics is the principle of conservation of energy, which states that energy cannot be created nor destroyed. The increase of internal energy $(\otimes \mathrm{E})$ of a given system is equal to heat $(\mathrm{Q})$ absorbed from the surroundings plus the mechanical work (W) added. A more technical definition is in the next model [4]:

$$
\mathrm{Q}+\mathrm{W}=\otimes \mathrm{E},
$$

where: $\mathrm{Q}$ is heat, in $\mathrm{kJ} ; \mathrm{W}$ - work; $\otimes \mathrm{E}$ - increase of internal energy.

A heat processor/convertor is a device that produces net positive work as a result of heat transfer from a high temperature body to a low-temperature body. The thermal efficiency of such a device is defined as the ratio of output (energy sought) to the input (energy that costs). The input or the energy that costs is the heat from the high temperature source (indirectly, the cost for the fuel) [4]:

$$
\eta=\frac{W_{s}}{Q_{c}},
$$

where: $\eta$ is thermal efficiency; $\mathrm{W}_{\mathrm{s}}$ - energy sought; $\mathrm{Q}_{\mathrm{c}}$ - energy that costs.

\section{Experimental setup and results}

\subsection{Experimental setup for testing}

In order to gain the proper experimental results and to make some interesting observation in relation with the automotive waste recovery and conversion in the combustion chamber there were 
designed and installed specialized experimental equipment similar to those from figure 5 and figure 6.

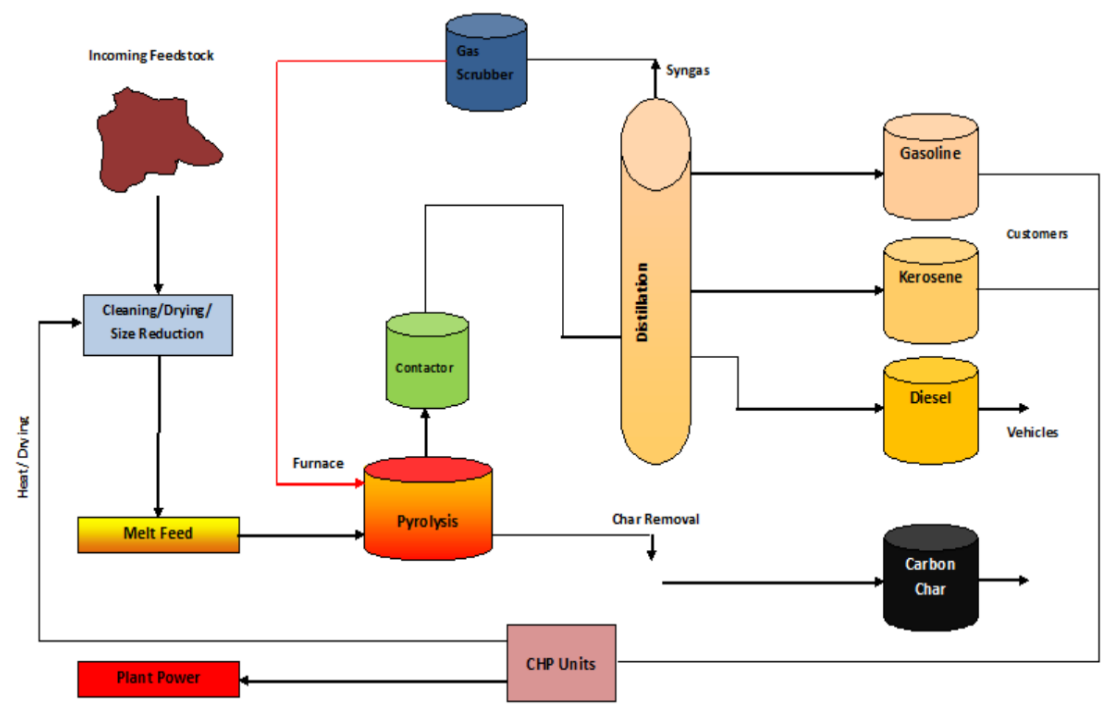

Figure 5. Pyrolysis process flow-a complement to plastic recycling [5].

In this period, a great amount of the plastic waste components are still treated as "waste," and there is a significant opportunity to recycle more of the plastics we use in the automotive sector as shown in figure 6. Factors that currently limit mechanical recycling include: contamination issues (e.g., food waste), technical challenges of separating resins in mixed resin products, and lack of markets for some plastics. While technically all thermoplastics can be recycled, the conditions identified above can make recovery through mechanical recycling economically impossible. The result is that many plastics still are not recovered at end-of-life [5].

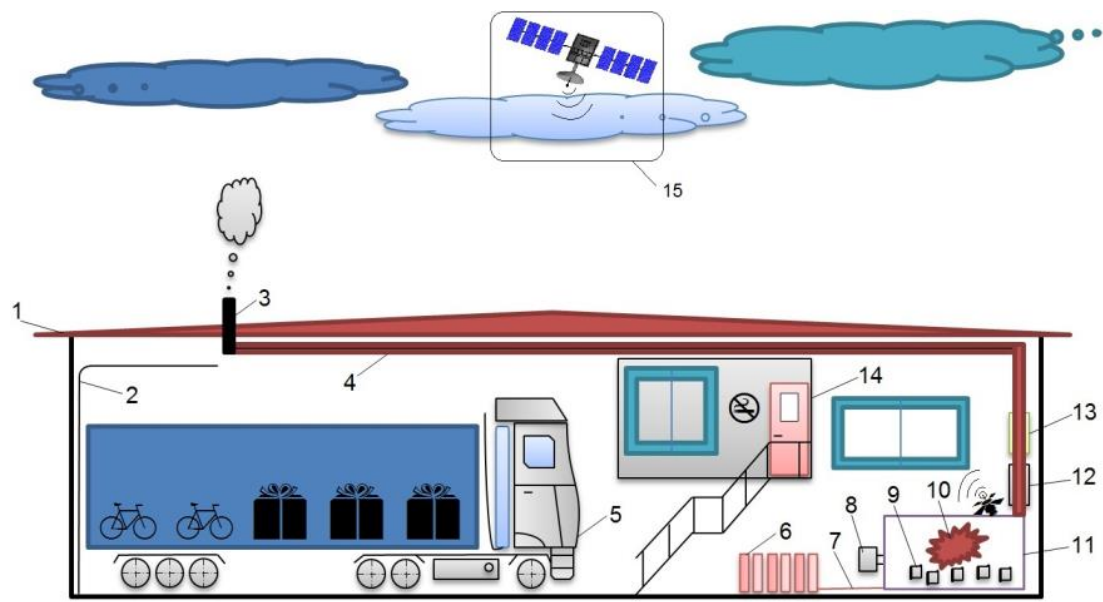

Figure 6. Experimental test site for automotive waste products recycle and thermal conversion

1-specialized space fot transport activities; 2-thermal insulator door; 3-periferic component for exhaust system and after-treatment of the gas emissions; 4-tube system for exhaust gases produced after combustion process; 5-transport truck in stand by state/repair/revision/inspection etc.; 6-radiator/heat exchanger; 7-thermal fluid system; 8-door for combustion chamber wastefuel supply during thermal conversion; 9-flammable automotive waste products; 10-combustion

chamber; 11-unit for thermal conversion of waste products; 12-particle filter; 13-katalitic convertor; 14-administrative space; 15-satelit connection and Wi-Fi control of the entire system. 
Thermal system for implementing the advanced engineering method and recycle automotive waste through conversion, heat recovery and measurement consists of the following: the main incinerator with combustion chamber, a liquid pump, and heat exchangers/radiators is shown in figure 7.

Exhaust gases are treated in catalytic convertor and particulate filter in order to diminish the pollutants and toxic chemical components. The after-treatment system is sketched out in a simplified manner, but it may be developed further more to achieve desired level of pollution reduction.

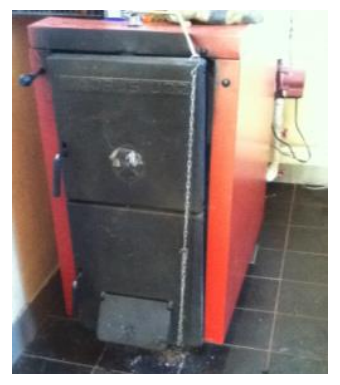

a

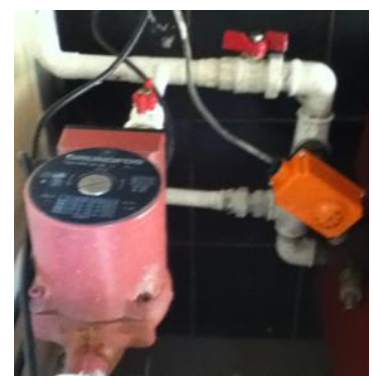

b

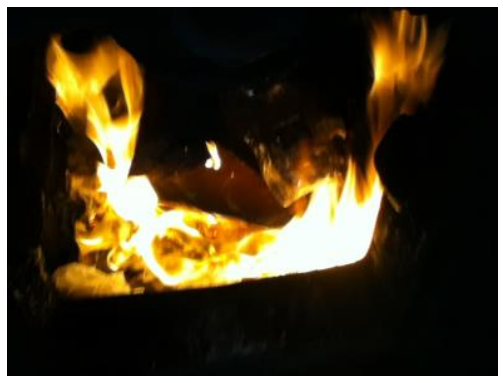

Figure 7. Experimental research components used to implement the automotive waste disposal concept. a-incinerator; b-liquid pump; c-combustion chamber in operation with flammable materials ignited.

\subsection{Experimental testing results}

By setting up a computer assisted testing model and measuring the temperature and automotive waste fuel consumption levels, as well as taking into consideration the pollution impact and carbon foot print value it may be assessed the conversion efficiency. The present paper makes a synthesis of experimental stage realized till now by implementing an advanced method with computer aided thermal conversion and management in the field of automotive waste recovery and reuse. The incinerator used in the conversion system is technically defined in table 1. The designed, implemented, tested and evaluated automotive waste recovery and conversion system is a now a fully operational model, which was analyzed concerning combustion proper development, waste management and auxiliary thermal transfer system in the studied area. A new method for automotive waste disposal was developed and deployed. The junction with computer science and processing power, as well as carbon economy is consistently supporting the pollution reduction process and waste disposal proper management with engineered methodology in advanced thermal conversion of automotive waste.

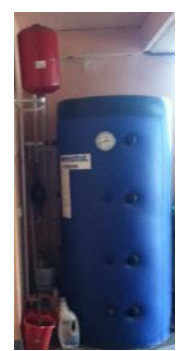

a

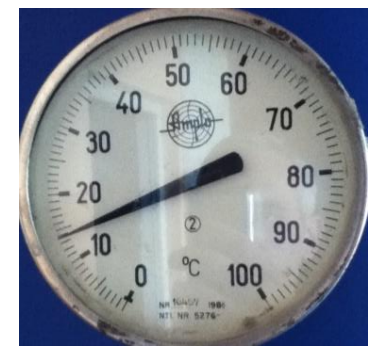

b

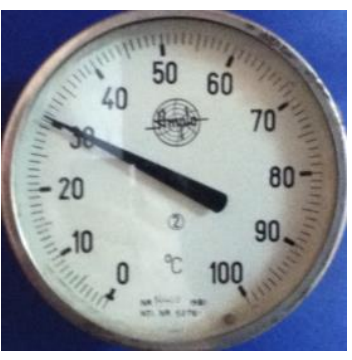

$\mathrm{c}$

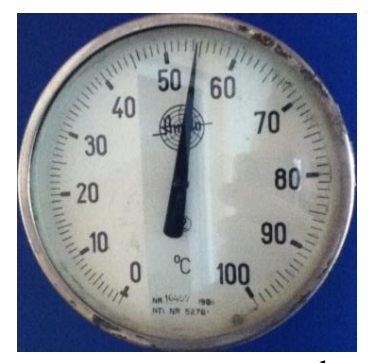

d

Figure 8. Heat storage tank (puffer) and temperature control.

a-puffer/heat storage unit; b-initial temperature of thermal agent; c-temperature in the puffer after three hours from fire starting time; d-temperature in the system after 5 hours of consistent burning. 
Table 1. Technical specs of automotive waste conversion unit.

\begin{tabular}{ll}
\hline Parameter & Real Value \\
\hline Manufacturer & Viadrus \\
Model & Internal combustion \\
Combustion chamber capacity & $200 \mathrm{dm}^{3}$ \\
Fuel type & Automotive waste \\
Particular components & Wasted fuel (diesel and petrol) \\
& Automotive plastics, filters, wood, oil \\
Standard fuel consumption & $3 \mathrm{~kg}$ waste products/h \\
Calorific power standard & $120 \mathrm{MJ} / \mathrm{h}$ \\
Average temperature & $50^{\circ} \mathrm{C}$
\end{tabular}

\subsection{Limitations of the proposed study}

The present work is limited to the development and implementing of the new and available engineering method in automotive waste disposal with the aid of computer power at a local transport company site, but it may be redefined and applied in some other contexts.

The proposed plan is applied properly in the present project for transportation unit, but further more needs revising in order to extend it for all types of waste (Figure 9).

For the present project the footprint is 1.58 metric tons per year. The average footprint for people in Romania is 4.16 metric tons. The average for the industrial nations is about 11 metric tons. The average worldwide carbon footprint is about 4 metric tons. The worldwide target to combat climate change is 2 metric tons [6].

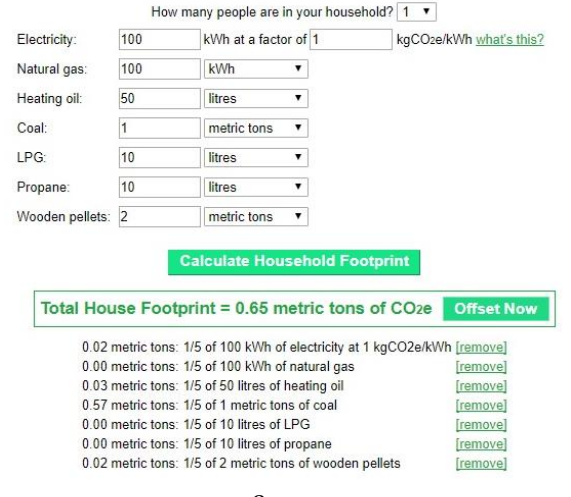

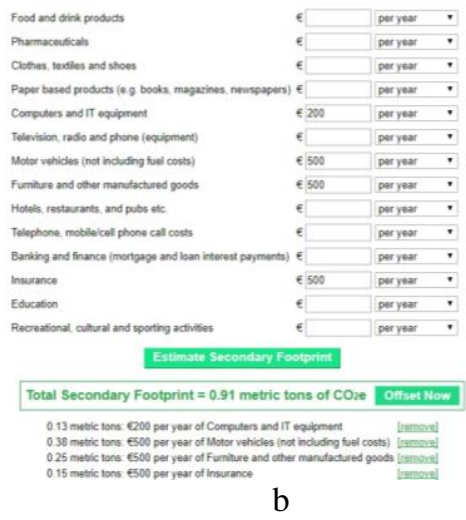

$\mathrm{b}$

Figure 9. Carbon foot print control.

a-Building carbon generation; b-Secondary carbon foot print calculator

\subsection{The novelty of the achievement}

The authors are experienced in researching computer aided manufacturing and specific automotive technologies. This is one of the few starting papers which combine aspects that define designing, manufacturing and automotive engineering methods based on computer processing power available in polytechnic approaches in order to diminish pollution level and contribute in waste management through recovery and thermal conversion based on latest technologies available in the sector.

\section{Conclusions}

Non-proper automotive waste disposal will lead in short period of time to more health problems and costly environmental damages. Advanced method in engineering aided waste disposal of automotive waste products is the solver of these problematic aspects by assembling technical instruments and procedures which transform in a practical way the pollutant components. The present paper had challenged the standards for integrated automotive waste disposal and management in relation with the engineering research. Emissions and carbon footprint parameters 
were also taken into consideration. They were analysed in correlation with the complex automotive industry and the transportation system which impacts the environment. The present article had shown that the automotive waste disposal if approached with advanced engineering methods of component after-treatment has also a financial impact. Further development possibilities are foreseeable in order to improve such studies of the problem concerning automotive waste disposal properly. This is the reason why we encourage the study of carbon impact of every activity in order to define properly the means to control the pollution.

\section{References}

[1] Wasilewski R 2013 Energy recovery from waste plastics Chemik International vol 675 pp 435-445

[2] *** 2016 Plastics - the Facts 2016. An analysis of European plastics production, demand and waste data http://www.plasticseurope.org/documents/document/20161014113313-plastics the_facts_2016_final_version.pdf

[3] Borzan AI et al 2017 Designing and testing a system for thermal-hydro-energetic conversion of flamable waste for a 200 square meters building Șiință și inginerie eISSN 2359 - 828X http://stiintasiinginerie.ro/wp-content/uploads/2017/05/56.

[4] Vlachopoulos J and David Strutt 2002 Plastics Technician's Toolbox vol 2, pp 21-33 http://www.polydynamics.com/heat_transfer_revised.pdf

[5] *** 2011 Conversion technology: A complement to plastic recycling https://plastics.americanchemistry.com/Plastics-to-Oil/

[6] *** 2017 Carbon calculator http://www.carbonfootprint.com/calculator.aspx 